\title{
Francisco Umbral, la génesis periodística de un escritor. Análisis de sus artículos radiofónicos en La Voz de León (1958-1961)
}

\author{
Manuel Fernández SANDE \\ Universidad Complutense de Madrid \\ manuel.fernandez@ucm.es \\ Eduardo MARTÍNEZ Rico \\ Universidad Complutense de Madrid \\ m.rico.003@cofm.es
}

Recibido: 24 de junio de 2015

Aceptado: 13 de agosto de 2016

\begin{abstract}
Resumen
Francisco Umbral inicia su actividad periodística profesional en la emisora La Voz de León, perteneciente a la REM -Cadena de radio del Movimiento-. Entre mayo de 1958 y febrero de 1961 dispone de una sección diaria para la que escribe un comentario a modo de columna radiofónica. En este artículo se analiza por primera vez este conjunto de textos inéditos que el propio Umbral conservaba en su domicilio, y que constituye una fuente de gran valor para conocer los orígenes periodísticos y literarios del escritor. Se profundiza en su etapa en León, realizando un análisis contextual, temático y estilístico de un total de 770 artículos radiofónicos pertenecientes a cuatro secciones: "Buenas noches", "El piano del pobre", "Buenos días" y "El tiempo y su estribillo".
\end{abstract}

Palabras clave: Francisco Umbral; Columnismo; Periodismo de opinión; Periodismo radiofónico; La Voz de León.

Francisco Umbral, the journalistic genesis of a writer: analysis of his radio articles in La Voz de León (1958-1961)

\begin{abstract}
Francisco Umbral began his professional activity as a journalist in the radio station La Voz de León, which belonged to REM - Franco's regime's network-. Between May 1959 and February 1961, he had a daily section where he wrote diferent communications as a type of radio columns. In this article, this group of unpublished texts that Umbral had preserved unpublished are analysed for the first time. They are a rich source of information for a knowledge of the author's journalistic and literary beginnings. We study in depth his years living in León, through a contextual, thematic and stylistic analysis of 770 radio articles from four different sections: "Buenas noches", "El piano del pobre", "Buenos días" and "El tiempo y su estribillo".
\end{abstract}

Keywords: Francisco Umbral; Columnism; Opinion Journalism; Radio Journalism; La Voz de León.

\section{Referencia normalizada}

Fernández Sande, M. y Martínez Rico, E. (2016) Francisco Umbral, la génesis periodística de un escritor. Análisis de sus artículos radiofónicos en La Voz de León (1958-1961). Historia y Comunicación Social. Vol 21, número 2, páginas 303-320. 
Sumario: 1. Introducción. 2. Inicios periodísticos de Francisco Umbral en León. 3. Análisis contextual y temático de los artículos radiofónicos en La Voz de León. 4. Un estilo en formación. 5. Significación literaria y periodística de estas colaboraciones. 6. Referencias bibliográficas.

\section{Introducción}

Este artículo pretende profundizar en los años de Francisco Umbral en León (1958-1961), sin duda su etapa profesional más desconocida. A pesar de tratarse de un corto periodo cronológico, suponen unos años decisivos puesto que en ellos inicia su actividad periodística en la emisora La Voz de León, y poco a poco comienza a publicar diferentes colaboraciones periodísticas en El Norte de Castilla y el Diario de León. Umbral llega a León sin apenas experiencia previa en la profesión, salvo las colaboraciones que publica en el diario Proa y la revista universitaria Arco, entre los años 1954 y 1956 (Fernández Sande y Martínez Rico, 2014), y los cinco artículos de crítica literaria publicados en El Norte de Castilla, entre marzo de 1957 y febrero de 1958. El trabajo en la emisora y su paulatina incorporación a los círculos periodísticos y literarios de León supondrá para Umbral un cambio vital y profesional que resultará decisivo para su posterior trayectoria. Nuestro objeto de estudio principal ha sido un corpus de colaboraciones radiofónicas muy extenso - cuatro secciones de radio-, en el que no es difícil ver los antecedentes de la columna periodística de Francisco Umbral.

León era la ciudad natal de su madre, en la que pasan varios veranos de su infancia, así como en Valencia de Don Juan, pueblo leonés origen de su familia materna. "El hijo de Greta Garbo" (Umbral, 1982) tiene a León como uno de sus espacios. A pesar de que el escenario más importante del libro es Valladolid, en la segunda parte los protagonistas se trasladan a León, y el escritor dedica un buen número de páginas a recrear sus vivencias infantiles en la ciudad. En el resto de sus libros y artículos las referencias a esta etapa son muy fugaces y fragmentadas. Para una obra tan extensa como la de Umbral, León suscita una atención literaria más que escasa.

El muy trabajado pero también fulgurante triunfo que el escritor conseguirá en Madrid en las décadas de los 60 y 70, su total consagración a la prensa y la literatura, sumen en cierto olvido aquel trabajo de juventud en la radio y prensa leonesa. El análisis de estos textos y de esta etapa trata de llenar una importante laguna en los estudios umbralianos.

Sobre los años de Umbral en León y sus inicios periodísticos en la ciudad, existen muy pocos estudios, trabajos que adquieren un extraordinario valor para conocer esta etapa. Juan Gracia $(1995,2003)$ en su tesis doctoral "El artículo diario de Francisco Umbral" y trabajos posteriores como "Orígenes del artículo diario de Francisco Umbral", es el primer autor que analiza con detalle sus comienzos periodísticos entre los que incluye esta actividad en La Voz de León. Anna Caballé (1999, 2004), con "Los comienzos de un escritor" y "Francisco Umbral. El frío de una vida", realiza 
una profunda investigación biográfica sobre las raíces del autor con la que aporta datos imprescindibles para conocer estos años del escritor.

Desde una perspectiva más amplia, otras fuentes de información importantes son los diferentes libros de ensayos monográficos o actas de congresos editados en los últimos años sobre la vida y la obra de Umbral dirigidos por los profesores Ardavín (2003), Celma, (2003) Sanz Villanueva (2009), De Buron (2009,2010), y J. Ignacio Díez (2012).

La obra periodística de Francisco Umbral y su estilo han sido estudiados en profundidad en las tesis doctorales de Francisco Javier Mayoral (1998), "Transgresión, insolencia y creatividad en la prosa diaria de Francisco Umbral 1976-1994", y Bernardo Gómez Calderón (2001), "La evolución del columnismo de Francisco Umbral (1961-1997). Aspectos retórico-argumentativos".

Este artículo presenta los resultados del análisis temático y estilístico de las colaboraciones radiofónicas de Francisco Umbral en La Voz de León entre mayo de 1958 y febrero de 1961, unas colaboraciones que en su gran totalidad se mantenían inéditas desde los años en que fueron emitidas, y que nos han sido facilitadas para su estudio por la Fundación Francisco Umbral. Juan Gracia en los trabajos citados describe estas colaboraciones e incluye como ejemplo el texto de una de ellas. Sanz Villanueva (2009:234) en "Francisco Umbral y su tiempo" informa sobre la conservación de estas colaboraciones radiofónicas de los años juveniles del escritor y recomendaba su publicación. Entre el 10 y el 14 de agosto de 2014 El Mundo publicó una muestra de cinco comentarios e informaba sobre la próxima edición por parte de Planeta de un libro que por fin recogerá una recopilación de aquellos textos con el título "Diario de un noctámbulo"'.

El valor de estos comentarios radiofónicos que Umbral escribió, y en muchos casos leyó personalmente en los micrófonos de la emisora La Voz de León, es muy alto, puesto que se trata de las primeras colaboraciones con periodicidad diaria de la carrera de Umbral. En cierto modo podríamos considerarlos, excepto la sección Buenos dias, textos escritos como auténticas "columnas radiofónicas", que constituyen un precedente directo de su trabajo posterior en el género de la columna personal, entendida como "artística síntesis entre la racionalidad y la subjetividad" (Casals, 2000: 47), que renovará y del que se convertirá en uno de los grandes maestros del columnismo español.

Los textos de estas colaboraciones radiofónicas los conservaba el propio escritor en su domicilio de Majadahonda en Madrid -"La Dacha"-. Textos mecanografiados en los que en algunos casos se pueden apreciar anotaciones manuscritas, con correcciones o pautas de ritmo para su correcta locución. En algunos casos también localizamos textos censurados por la oficina provincial de información y turismo en León que Umbral conservó entre los que finalmente fueron emitidos. El corpus total analizado está integrado por 770 comentarios radiofónicos, que se corresponden con cuatro secciones bien definidas que Umbral desarrollaría en la emisora en aquellos años: "Buenas noches" -se conservan 211 comentarios-, "El piano del pobre"-196-, 
"Buenos días" -85- y "El tiempo y su estribillo" -278-. Umbral experimentaría con cada una de las citadas secciones que presentan diferencias muy notables; esa estructura de su obra radiofónica en La Voz de León se refuerza al estar encuadernadas cada una de ellas en un volumen individual, excepto la sección "Buenos días", cuyos textos se conservaban en folios sueltos en una carpeta.

Otro grupo de textos conservados de esta etapa en la emisora es una serie emitida con el título "Crónica de las tabernas leonesas". Se trata de un conjunto de trece guiones que no forman parte de nuestro objeto de estudio, por no reunir las características del comentario radiofónico. Antes del fallecimiento del autor, en el año 2004, fueron rescatados para ser editados por primera vez en formato libro. La profesora De Buron-Brun (2013) los ha analizado en su trabajo "El barrio húmedo. Paseo por las tabernas leonesas."

Los artículos radiofónicos conservados se corresponden con todo este periodo 1958-1961. El primer texto es del 29 de mayo de 1958, fecha en la que se responsabiliza de la sección "Buenas noches". Salvo los festivos, en los que Umbral no escribe su comentario, se conserva toda la serie hasta el 4 de enero de 1959. Lo mismo sucede con la siguiente sección de comentarios radiofónicos, "El piano del pobre", cuyo primer texto corresponde al 7 de enero de 1959 y el último al 31 de agosto de 1959. No se conservan textos del mes de septiembre de ese año. Francisco Umbral abandona la ciudad para casarse en Valladolid el ocho de septiembre (Caballé, 2004:144), y posiblemente no regresa a León hasta final de mes. La tercera serie de comentarios se titula "Buenos días"; comienza el 5 de octubre de 1959 y finaliza el 30 de enero de 1960. Entre el 6 y el 19 de noviembre sólo se localiza el texto del 13 de noviembre. La cuarta y última sección radiofónica de Umbral en la emisora es "El tiempo y su estribillo"; el primer comentario corresponde al 1 de febrero de 1960 y el último al 4 de febrero de 1961. Umbral abandonó la ciudad de León el lunes 6 de febrero. De la serie "El tiempo y su estribillo" no se conservan los textos del 1 de julio al 26 de julio de 1960; desconocemos si la razón es que Umbral no escribió comentarios durante esas semanas o si se perdieron los originales.

El análisis de estas colaboraciones requería también una investigación histórica sobre la actividad periodística de Umbral en León. Entre las fuentes de información primaria utilizadas, las hemerográficas han sido importantes. Se ha procedido a una revisión del contenido de los dos periódicos principales de la provincia de León: Diario de León y Proa entre enero de 1958 y marzo de 1961. Esta revisión persigue diferentes objetivos: localizar tanto las colaboraciones publicadas por Francisco Umbral durante esos años como informaciones sobre su actividad en la ciudad. Juan Gracia aporta un estudio muy exhaustivo en su tesis doctoral, con anexos que incluyen todas estas referencias. Nosotros hemos cotejado esa información con las fuentes originales, y se ha localizado algún texto que hasta el momento no se había indizado; por ejemplo "Plenitud y poesía" publicado el 24 de marzo de 1957 en El Norte de Castilla, y otros textos publicados por Umbral en El Diario de León. Han sido fuentes útiles para conocer el contexto sociopolítico y periodístico, las programaciones de la emisora La Voz de León, así como para realizar la comparación de sus colaboracio- 
nes en prensa con las que escribía para la radio. Estos periódicos también resultan imprescindibles para comprender la realidad sociopolítica y periodística que Umbral encuentra en la ciudad. Asimismo, se ha consultado el diario vallisoletano El Norte de Castilla entre marzo de 1957 -en el que Umbral publica artículos de crítica literaria- y marzo de 1961. En este diario se han localizado todos los artículos publicados por Francisco Umbral en la sección "Las Artes y Las Letras" y las crónicas informativas que envía desde León cuando se convierte en el corresponsal del periódico de Valladolid en la ciudad, publicadas entre el 15 de octubre de 1960 y el 4 de febrero de 1961.

Las principales fuentes de información utilizadas, además de las propias colaboraciones radiofónicas ya descritas han sido una serie de entrevistas en profundidad realizadas con diferentes personas que mantuvieron contacto directo con Francisco Umbral en aquellos años: su primo, José Antonio Pérez Perelétegui, hermano de José Luis, director de la emisora; diferentes compañeros: Aurora Fernández -administradora de La Voz de León-, Manuel Tomé -locutor de la emisora- y César Aller- responsable de la sección de cultura del periódico Diario de León.

Otra fuente de información esencial es el testimonio directo del propio Umbral sobre sus años en León, diseminado a lo largo de su obra literaria y periodística. Por otra parte, en los diferentes libros de conversaciones con Francisco Umbral, publicados por los autores Mactas (1984), Herrera (1991), y Martínez Rico (2001,2003), también se han localizado comentarios del escritor sobre sus años en León que constituyen un testimonio directo de gran valor.

\section{Inicios periodísticos de Francisco Umbral en León}

La afición literaria de Francisco Umbral es muy temprana, y se la inculcó su madre, una mujer muy culta e interesada por las letras (Martínez Rico, 2001: 23). Umbral, como ya se ha dicho, escribe en publicaciones universitarias y en El Norte de Castilla, pero no dejan de ser publicaciones esporádicas y no profesionales. Su primera dedicación profesional dentro del periodismo es en $L a$ Voz de León. Pero el primer trabajo de Francisco Umbral fue antes, en el Banco Central de Valladolid, donde ingresó como botones a los catorce años (Caballé, 2004: 103), y allí permaneció realizando diferentes tareas, por ejemplo ordenanza, hasta abril de 1958, mes en el que abandonó la ciudad para trasladarse a León.

José Luis Pérez Perelétegui, primo de Umbral, es nombrado director de la emisora La Voz de León -perteneciente a la Cadena REM, Red de Emisoras del Movimiento, conocida en la ciudad como Radio Falange-, y consciente de las escasas posibilidades de promoción de su primo en el Banco Central, le ofrece trabajo allí. Umbral, que en aquellos momentos tenía veintiséis años, entra en principio como auxiliar administrativo, pero José Luis sabía que la cultura y la habilidad para escribir de su primo le harían ascender pronto. Y así fue; entre otras labores, Umbral escribe las 
cuatro secciones radiofónicas que ya hemos señalado como el objeto de análisis de este estudio.

Umbral comienza su trabajo en La Voz de León, plenamente consciente de que es su gran oportunidad profesional, y trabajará con el máximo tesón para aprovecharla. En la estación, los textos que comienza a escribir en su puesto en el despacho de administración rápidamente llaman la atención por su calidad. El joven recién llegado de Valladolid sorprende a todos los compañeros por su cultura literaria, y poco a poco comienza a ganarse su aprecio. Los compañeros de la emisora entrevistados para este trabajo recuerdan a Umbral -Paco Pérez en sus inicios en la emisora- como una persona muy reservada, tímida, incluso un tanto huraña; hablaba muy poco y no le conocían apenas amigos. Cuenta con el apoyo incondicional de su primo, director de la emisora, pero muy rápido su talento no pasa desapercibido en la emisora: "Su evolución en la emisora fue increíble, era muy listo", recuerda Aurora Fernández ${ }^{2}$ Otros rasgos de su carácter comienzan a aflorar en su etapa leonesa, por ejemplo su gusto por la provocación y un cierto "esnobismo", según coinciden en señalar Manuel Tomé y José Antonio Pérez Perelétegui ${ }^{4}$, que recuerdan a Umbral con un llamativo abrigo blanco y una melena incipiente que le daban un cierto aspecto bohemio, rasgos que Umbral no dejará de acentuar en etapas posteriores para construir su imagen pública. También sus compañeros recuerdan que Umbral comenzó a destacar por su carácter contestatario, y una tendencia ideológica liberal que resultaba cuando menos chocante en la época para una emisora del Movimiento.

Ya sabemos que en esta etapa leonesa Umbral contrae matrimonio el ocho de septiembre de 1959 en Valladolid, con su novia de siempre, España Suárez, la mujer que le acompañará durante toda su vida. Su trabajo en La Voz de León le ha dado la estabilidad económica suficiente para poder dar este paso que sin duda resultó fundamental para él.

Además del trabajo en la emisora, Umbral desempeña otras actividades, siempre relacionadas con la cultura y el periodismo. Llegará, al final de esta etapa, a conseguir una columna diaria en el Diario de León, algo que para él debió de constituir un gran éxito (Gracia Armendáriz, 2003b: 88), y del que no volverá a disfrutar hasta mucho después en su carrera. También contará con la confianza de Miguel Delibes, que le hará corresponsal de El Norte de Castilla en León. Umbral se relacionará, por otra parte, con los ambientes culturales de la ciudad, algo que se hace patente por ejemplo en su labor de organizador de unas conferencias culturales del Círculo Medina, dependiente de la Sección Femenina. Umbral elige a los conferenciantes y dirige los coloquios, algo muy importante para él, si tenemos en cuenta que gracias a este ciclo logra conocer a gente como César González-Ruano, tal vez la persona que él más admiraba en aquel momento, su maestro en el articulismo (Gómez Calderón, 2003:224).

También dirige un cine-club que le encarga el Círculo Medina. Precisamente su marcha de la ciudad, que bien podemos calificar de expulsión, se ve provocada por esta actividad. Presenta la película "Orfeo", de Jean Cocteau, y es muy mal recibida 
por el público leonés (Caballé, 2004: 151-152). Umbral se muestra muy contrariado. Hay que destacar que en sus artículos radiofónicos, Umbral arremete con frecuencia contra León y los leoneses, y en este caso vuelve a hacerlo por este motivo concreto.

Umbral ya debía de ser considerado "persona non grata" para las autoridades de la ciudad por sus constantes escritos críticos que se pueden observar en el corpus analizado. El escritor y periodista mantiene una polémica en los medios con Delfina García Cela, presidenta del Círculo Medina y máxima responsable de la Sección Femenina en León. El caso desencadena una feroz campaña de prensa en contra de Umbral dirigida por el diario Proa, órgano oficial del Movimiento, y su director Federico Miraz ${ }^{5}$, con el que Umbral había generado una fuerte enemistad en sus años en la ciudad (como se puede comprobar por diferentes comentarios críticos o despectivos que fueron realizados sobre su labor en los comentarios radiofónicos de Umbral). El caso de Umbral llegó a tratarse en un pleno del Ayuntamiento ${ }^{6}$, y es el alcalde de la ciudad, José Martínez Llamazares, el que exige finalmente su destitución a José Luis Pérez Perelétegui, que al principio pone a su disposición su cargo, solidarizándose con su primo.

Umbral había empezado a escribir su columna diaria en el Diario de León, en un tono muy diferente al de sus artículos periodísticos, tono muy informativo que podríamos calificar de políticamente correcto. Pero tiene que abandonarla.

El cuatro de febrero de 1961, Umbral acude a la emisora para leer el último de sus comentarios de "El tiempo y su estribillo". Ni en su texto radiofónico ni en su columna del periódico de ese día hace una sola referencia a su marcha. Umbral no se despide ni de sus oyentes ni de sus lectores; se marcha sin aspavientos, resignado a iniciar una nueva vida. Elige como último tema, tanto de su comentario radiofónico como de su columna, la sesión del cine-club del Círculo Medina que tendría lugar al día siguiente. Umbral hace la crítica cinematográfica de la película de Lamorisse "El globo rojo", sin referencia alguna a los incidentes protagonizados, ni ninguna ironía o expresión que pueda resultar susceptible ${ }^{7}$. En un claro golpe de efecto intencionado decide marcharse informando sobre la misma institución que había provocado su despido.

La documentación consultada y los testimonios orales confirman que la salida de Umbral de León se ve forzada por la sanción que implica su despido de la emisora, y por tanto no se debe a una decisión voluntaria del escritor (Mactas, 1984:46). Algo diferente es que Umbral no proyectara para el futuro su marcha a Madrid para continuar con su carrera literaria y periodística (Martínez Rico, 2003:38-39).

A pesar de una salida tan brusca de la ciudad, Umbral ha conseguido en sus años en León hacerse periodista y ganar seguridad en sí mismo. 


\section{Análisis contextual y temático de los artículos radiofónicos en La Voz de León}

El paso por La Voz de León se podría entender como la gran oportunidad de Umbral, tal vez de toda su vida. Lleva doce años trabajando en el Banco Central de Valladolid, sin apenas promocionarse, y las posibilidades que se le abren en $\mathrm{La} \mathrm{Voz}$ de León encajan muy bien con su vocación literaria y periodística. Umbral tiene un gran número de lecturas literarias (le gustan especialmente Larra, Gómez de la Serna y Valle) y articulísticas: Foxá, D'Ors, Eugenio Montes... (Gómez Calderón, 2004: 79-96). Está muy preparado cultural y literariamente.

La primera sección en la que trabajará Umbral será "Buenas noches". Empieza en mayo de 1958; no era un espacio de producción propia, y ya se venía realizando desde finales de 1957. María Teresa Yñigo de Toro había comenzado el 13 de marzo de 1956 a cerrar la emisión de La Voz de Valladolid con este comentario. "Un breve trozo de literatura radiofónica arropada en la hora callada y romántica de la medianoche", en palabras de su propia autora, quien años más tarde publicaría en libro una antología de sus comentarios (Yñigo de Toro, 1963: 5-6). La sección comenzó a emitirse también en León y encantó a los oyentes, hasta el punto que la dirección de la emisora se decidió por incorporar un cierre de emisión similar. Parece muy probable que Umbral hubiese escuchado a Yñigo en Valladolid, pero sin duda en León tendría conocimiento de sus célebres textos nocturnos, por los que la locutora recibiría un Premio Ondas en 1961. Se percibe una clara influencia de los comentarios de Yñigo en los de Umbral, ya que utiliza la misma fórmula de arranque y el mismo tono lírico. Francisco Umbral comenzó a participar de estos turnos del "Buenas Noches" casi desde su llegada a la emisora; la calidad de sus textos decide a José Luis Perelétegui a confiarle la sección que solían leer los locutores del turno de noche.

La hora de emisión habitual era de 00:45 a 00:50. Es muy sintomático que Umbral empiece esta sección dedicándole el primer artículo a Juan Ramón Jiménez $\left.{ }^{8}\right)$, del que llegó a decir que fue uno de sus padres literarios (Umbral, 1996: 38-41), por referirse al poeta y por referirse a la poesía, capital en su obra (García Posada, 2009: 7-26).

"Llevaste nuestra poesía a la más alta cumbre de depuración a que llegara ni pudiera llegar jamás. Creaste un siglo de poesía. De ti ha nacido toda la lírica española posterior a ti."

Umbral siempre quiso ser escritor, en libro y en periódico, pero pronto empieza a distinguir la sutil diferencia que muestra lo que se escribe para la radio, y lo cuenta con su particular manera literaria.

"Esta es la gran aventura de la palabra pronunciada ante el micrófono. Uno está aprendiendo a diferenciar, aprendiendo a situarse según si escribe para la imprenta o escribe para el aire. Nuestra palabra impresa goza un destino seguro, previsto; tiene por decirlo así, un destino burgués. Pero la palabra pronunciada nos sale aventurera, volandera",

En esta etapa, y en esta sección de "Buenas noches", Umbral encuentra su pseudónimo literario. En León había un escritor que se llamaba igual, Francisco Pérez, 
y publicaba en el Diario de León. Con el inicio de la nueva temporada radiofónica decide firmar sus colaboraciones radiofónicas con el pseudónimo de Francisco Umbral, hecho que han recordado estudiosos como Jean-Pierre Castellani (2012: 281).

En toda la sección de "Buenas Noches" apenas existen referencias a la actualidad política local. Posiblemente Umbral todavía no se siente lo suficientemente conocedor de la ciudad. Las referencias literarias son constantes en sus comentarios, que en general mantienen un elevadísimo tono cultural. La libertad temática es muy amplia, Umbral dedica su comentario de madrugada para saludar a distintas profesiones, a diferentes escritores, a sus ciudades favoritas, etc. El tono de los textos está repleto de lirismo, y el comentario le ofrece la oportunidad de experimentar con el lenguaje y emular a sus admirados columnistas de Madrid.

Los textos radiofónicos de "Buenas noches" tienen una extensión habitual entre las 325 y las 350 palabras. Umbral se siente cómodo, y mantendrá esa extensión en las sucesivas secciones que escribirá en la emisora, excepto "Buenos días".

La temática de las colaboraciones radiofónicas pertenecientes a la serie "Buenas noches" y la posterior "Piano del pobre" es muy diversa. Destaca una honda preocupación social del autor. Por ejemplo, Umbral denuncia desde su micrófono, en diferentes ocasiones, el trabajo infantil que se puede ver en León como en tantas ciudades de la España de finales de los 50. Una muestra muy interesante de este trasfondo ideológico de Umbral en la época, lo encontramos en su comentario "Buenas noches, burgués" 10 .

"La aristocracia supervive en una dorada y pintoresca jubilación; la burguesía se ha hecho cargo de responsabilidades y privilegios sustituyendo a su modo las antiguas soberanías. Y ahora es a otra clase de más abajo a quien parece haber llegado el turno histórico. El proletariado llama a la puerta condecorada del burgués, como este llamó un día a la cancela heráldica del aristócrata"

Umbral escribe todos estos artículos en un momento muy determinado, el franquismo, con todo lo que eso implica. La Voz de León es una emisora de Falange Española. No parece en absoluto que se una a la retórica franquista, sino que mantiene un tono crítico y poco condescendiente con el régimen para la época. Sin embargo, sí se localizan tres o cuatro comentarios dedicados a glosar efemérides del Régimen, como el llamado "Día de la Victoria"11.

La sección de "El piano del pobre" responde al deseo de Umbral de que su estilo brille aún más si cabe. De una canción francesa interpretada por Patachou, "El piano del pobre", Umbral toma de ella tanto el título de la sección como su sintonía ${ }^{12}$.

El nuevo comentario radiofónico de Umbral pasa a ser matinal. Su hora de emisión será las 10:55; la extensión, muy similar a "Buenas noches", oscila entre las 325 y las 350 palabras. En realidad no existen grandes diferencias estilísticas ni temáticas entre ambas secciones. 
Umbral va a utilizar la sección -como ya venía haciendo en "Buenas noches"-para experimentar con su escritura y dejarse llevar por una absoluta libertad temática. Hasta que consiga el éxito periodístico en Madrid, nunca volverá a tener tanta libertad como la que disfruta en esta etapa en La Voz de León.

Umbral construye sus comentarios radiofónicos teniendo bien presentes muchos de los principios que van a constituir su concepción del artículo periodístico. Sus textos son una suma de "información, subjetividad, verdad momentánea y lirismo" (Gómez Calderón, 2004: 103). Pero algunos presentan un carácter más lírico, otros más ensayístico, irónico, subjetivo o informativo.

En la sección del "Piano del pobre" Umbral no renuncia a incluir referencias literarias, pero desciende el tono culturalista. Incorpora poco a poco nuevos recursos; algunos los utilizará con profusión en el futuro, como cierta crónica social. Dedica numerosos textos o menciona en ellos a actrices famosas -Sofia Loren, Elizabeth Taylor-, cantantes -Elvis Presley-, personajes de la realeza o la aristocracia -princesa Soraya, príncipe Rainiero, príncipe de Gales-. A su vez sigue escribiendo sobre arte, literatura, cine...y se mantiene cierto perfil costumbrista: escribe sobre el martes y trece, la llegada del verano o las fiestas.

Un recurso que repite con frecuencia es tomar una información de agencia, y sobre ella desarrollar su texto: un aniversario de la Torre Eifell, el matrimonio de Aki-Hito, una noticia sobre coleccionismo de fonógrafos, o el desvanecimiento de un soldado de la guardia suiza. Cualquier anécdota o información intrascendente es suficiente para que Umbral hilvane su comentario del día.

En "El piano del pobre" Umbral expresa muchas de sus grandes pasiones: la literatura, la pintura, los animales, la ciudad de Madrid, que tan poco conoce todavía pero de la que ya se muestra fascinado. También los niños, y en general la infancia, motivan comentarios de Umbral, y para ellos siempre reserva su mejor tono lírico. En una ocasión llevan a la emisora una niña que se ha perdido, y Umbral escribe un bello comentario que recuerda de forma inevitable a "Mortal y Rosa" 13 .

\footnotetext{
"De vez en cuando, nos traen a la radio un niño que se ha perdido. Esta vez ha sido una niña.(...)Los niños viven otro tiempo que los mayores, y por eso se pierden. Los niños no viven nuestro tiempo adulto, sino otras horas más lentas y más rápidas a la vez. El niño siempre va por delante o se queda rezagado. Porque su tiempo no es el nuestro, resulta imposible que el niño camine al lado de uno."
}

Ya aparecen, aunque sea de forma fugaz, elementos característicos de su escritura posterior, como la ironía, el humor, la sensualidad, el erotismo, entre otros. Un jovencísimo Umbral ya escribe sus comentarios radiofónicos como si se tratasen de poemas en prosa, posiblemente su apuesta estilística más decidida. Él mismo así lo expresa en uno de sus textos: "Hagamos el poema en prosa de la cerveza, amante rubia de verano..." 14 Sus descripciones incluyen metáforas que sorprenden al oyente, como esta de una noche veraniega en la ciudad: "El cielo estaba gótico de constelaciones, gótica la noche de julio, con nuestras torres catedralicias que se veían de todas partes" $"$. 
La creación de la sección de "Buenos días" por parte de Umbral responde a una nueva temporada radiofónica. Se trata de un saludo matinal que vendría a ser el reverso diario de "Buenas noches", y significa la sustitución de "El piano del pobre", que desaparece de la programación. Umbral decide modificar por completo el estilo de su comentario para hacer algo mucho más lírico. El comentario es mucho más breve; suele ajustarse a unas 160 palabras.

Se trata de una sección eminentemente poética, y no hay que olvidar que Umbral, en origen, y también por esta época, quería ser poeta. En sus comentarios matinales va saludando a los más diversos personajes, objetos, profesiones, acontecimientos... pero siempre respetando el formato elegido. Los textos tienen ciertas influencias de las greguerías de Ramón Gómez de la Serna, que también había desplegado su literatura en la radio, y por la riqueza de metáforas tiene relación con otro de sus poetas favoritos, Pablo Neruda ${ }^{16}$.

La sección en su conjunto mantiene una calidad bastante irregular; la fórmula se le agota rápido a Umbral, por lo que decide abandonar este comentario matinal el 30 de enero de 1960, tan solo cuatro meses después de iniciarlo. Del conjunto de secciones analizadas es la más efímera.

"El tiempo y su estribillo" es la cuarta y última sección analizada en el presente artículo. El uno de febrero comienza esta nueva sección, para la que selecciona como sintonía "Pobre Gente de París", un tema que poco tiempo antes había sido un éxito en la radio en la versión instrumental de la orquesta de Les Baxter-. De nuevo elegía una melodía con aires franceses para el fondo de su comentario radiofónico. La sección supone una ruptura temática respecto a todas las anteriores que había realizado en la emisora. Abandona la absoluta libertad temática con que había escrito sus "Buenas noches" o "El piano del pobre" para dedicar su glosa radiofónica a comentar la actualidad leonesa. El horario es de máxima audiencia. Umbral siempre lee personalmente sus textos, "con una voz impostada que podía llegar a resultar altiva", según recuerda el poeta César Aller ${ }^{17}$.

Con la nueva sección se convierte en verdadero cronista de la ciudad. Pierde libertad temática, pero ganará una gran notoriedad pública en la ciudad, para bien y para mal. "El tiempo y su estribillo" será la sección que mantenga durante más tiempo en antena, un año completo.

Los comentarios de Umbral se impregnan de una mayor actualidad informativa local; sus textos mantienen un severo tono crítico, acompañado de su característica ironía. En muchas ocasiones se mueve en el límite de lo tolerado por el régimen franquista. La presencia de su primo al frente de la emisora debía de hacerle sentirse más seguro y libre ante el micrófono. El espíritu contestatario que en algunas de sus colaboraciones anteriores se podía intuir ante el tratamiento de temas generales o abstractos, comienza a aplicarlo en asuntos más domésticos, más locales, y eso al cabo de un tiempo acabará generándole problemas. En "El tiempo y su estribillo" emergen nuevos rasgos umbralianos que se convertirán en algunos de sus signos de identidad en el futuro, uno de ellos su querencia por la polémica. Dentro de los 
márgenes permitidos por la censura, y camufladas muchas veces con la mencionada ironía para eludirlos, Umbral se enzarza en disputas frecuentes con periodistas de otros medios o con responsables de diferentes actividades de la ciudad, especialmente el ayuntamiento, lo que a la larga provocará la expulsión de Umbral de la emisora y de la ciudad.

Umbral informa sobre los actos culturales, denuncia deficiencias en las obras públicas, comenta novedades en la administración municipal, reclama la creación de un nuevo hospital... Sigue mostrando una gran sensibilidad ante el tema social; denuncia desigualdades que se registran en la ciudad, así como el trabajo infantil, el analfabetismo, las viviendas obreras, las condiciones de trabajo de los mineros. Otro tema muy presente es su preocupación por el sistema de enseñanza

Los comentarios de esta sección se ajustan a una extensión que oscila entre $375 \mathrm{y}$ 425 palabras, ligeramente más largos que "Buenas noches" y "El piano del pobre". En el primero de sus comentarios, presenta la sección y explica el sentido de su título:

"Para ponerle el tiempo a su estribillo, su coletilla a la vida que pasa, vamos a inventarnos la diaria cantinela, con mejor moral que moraleja, dando más a la prosa que a la prosopopeya. En la provincia ocurre poca cosa. En la provincia nada ocurre, sino que ocurre el tiempo -nada más y nada menos- y al tiempo le pondremos su estribillo"18.

Es importante hacer una referencia a la censura ejercida sobre los textos de Umbral, como resultaba normativo con todos los guiones radiofónicos en el franquismo. Muchos de los artículos analizados cuentan con el sello de la Delegación de Información y Turismo, que suponía la conformidad para su emisión. Sin embargo, se localizan dos guiones tachados con una gran aspa y un sello de "Denegada" junto a alguna anotación del censor.

El primero de ellos, que tomamos como muestra, recoge un tema que también será recurrente en los comentarios radiofónicos de Umbral en León, y que acompañará al escritor durante gran parte de su obra posterior; nos referimos al llamado "gamberrismo", con el que tanto le gustaba hacer juegos literarios. A los "gamberros" les manifiesta toda su simpatía porque representan para él la rebeldía ante un orden social injusto y se suma a ellos en su subversión. El tema volvía a ser más que inconveniente en una sociedad militarizada y tan conservadora como la de la época.

"Buenas noches, gamberro, destrozón metafísico y rebelde, buenas noches. (...) Eres un altruista negativo (...) Al menos por esta noche, me voy contigo, gamberro. Cojamos piedras y empecemos a pedradas. Tú por aquí y yo por allá. Vamos a escandalizar al vecindario: a golpear en todas las puertas, a perseguir perros y fundir bombillas... Vamos a insultar a los serenos y salir corriendo. Grita fuerte, gritemos juntos; hay que enronquecer cantando disparates"19. 


\section{Un estilo en formación}

Uno de los datos más interesantes que aprendemos con estos artículos es que Umbral, a los 26 años, ya tenía una personalidad muy parecida a la que más adelante mostraría: la personalidad heterodoxa, creativa y contestataria que la mayoría de sus lectores conocen. Se muestra muy seguro de sí mismo en sus juicios, en todo lo que dice y en su actitud hacia el pueblo leonés y hacia sus autoridades; muchas veces se muestra ofensivo, incluso inconsciente, teniendo en cuenta que se estaba jugando su puesto de trabajo. Ya se atisba aquí rasgos de su personalidad: "Umbral prefiere molestar, herir sensibilidades, romper con lo establecido. A Umbral parece que le divierte suscitar odios, enemistades y antipatías" (Mayoral, 1998: 192). El carácter de este Umbral de 26 años es muy parecido al del Umbral maduro, e incluso al del Umbral de la última etapa.

Pero desde el punto de vista del estilo sí que cambió. Umbral se hizo más virtuoso con su herramienta, el lenguaje, con el tiempo, pero ya escribía muy bien con 26 años. La lectura completa de los textos permite advertir que su estilo evoluciona mes a mes aunque en todo momento resulta bien reconocible y que el joven periodista experimenta ideas. El análisis de sus colaboraciones radiofónicas en la emisora permite observar su evolución. Los comentarios radiofónicos de sus primeros meses en la ciudad se decantan por el estilo en el que Umbral en ese momento se siente más cómodo, el periodismo literario, personalista, subjetivo, en ocasiones incluso de tono lírico. Todavía no conoce las claves de la actualidad política o social leonesa, por lo que no sorprende que el joven Umbral procure destacar en el terreno que mejor dominaba.

Javier Mayoral (1997), en su tesis doctoral analiza el estilo de Umbral en el período 1976-1994. La personalidad transgresora, insolente y creativa de Umbral se muestra en una serie de hechos lingüísticos, muy bien analizados por el profesor, que están presentes en nuestras colaboraciones radiofónicas de forma más tenue. Aunque muestra esa misma personalidad heterodoxa y transgresora, la deja traslucir en sus hechos lingüísticos de forma menor. Su estilo es más conservador y lineal de lo que será después. Con el tiempo Umbral afilará sus formas verbales, sintácticas, textuales.

Sin duda en la formación de ese "instrumento", de ese estilo, y también en la forma de ver la realidad, de construir esa particular mirada sobre el mundo, la poesía es fundamental. Umbral siempre se confesó un lector de poesía por encima de otros géneros, y en origen quiso ser poeta. Buena parte de su éxito como prosista, como él mismo decía, consistió en aplicar los recursos de la poesía a la prosa. Umbral conocía muy bien la obra de los poetas, de muchos poetas, españoles y extranjeros, y fue crítico de la revista Poesía Española. Adapta la escritura poética a la periodística, utilizando en sus libros y artículos recursos, citas y reminiscencias poéticas como lo más natural, totalmente integradas en la frase periodística.

Así, por ejemplo, en el artículo "Buenas noches, estatua", de la sección "Buenas noches", escribe: "Buenas noches, estatua, vigía de bronce en los altos naufragios de 
la tarde, buenas noches"20. Identifica la estatua con un vigía hecho de bronce ante los crepúsculos, realizando, digamos, una traducción imposible a la realidad. Eleva el tema de su artículo a otro plano, el de la poesía, para decir con más intensidad lo que quiere decir. Hay aquí una trasposición metafórica que le resulta muy útil a Umbral, en cuanto a generadora de contenido y estilo. Ya desde estos primeros pasos de su carrera periodística decide ser prosista, pero con todas las ventajas que le ofrece el dominar, dentro de la prosa, el lenguaje poético.

Más adelante dice: "Eso es la posteridad, estatua: un fotógrafo de jardín público." El desarrollo de esta imagen le sirve para expresar una serie de ideas sobre las estatuas, sobre las estatuas en los parques. Y en esta dirección habla del "inmortal", la persona que representa la estatua, "presidiendo su breve olimpo de rotondas con niñeras". En lo que percibimos, por otro lado, el más genuino estilo umbraliano asomando aquí, lo que él llamó "la rosa y el látigo" para sintetizar y explicar su estilo. Umbral potencia la poesía, el lirismo, "la rosa", con ese carácter suyo, duro, contestatario, "el látigo". El "látigo" podría ser una "navaja", pero manejada con una asombrosa maestría. También sabía manejar "la rosa", con maestría, más todavía la conjunción de ambos elementos en su prosa.

"El tiempo y su estribillo" nos sugiere cómo "el tiempo", la realidad, la actualidad, le da el tema al articulista, mientras que él pone "el estribillo", es decir, el comentario, la poesía. Esto es clave para entender el arte periodístico de Umbral, desde este momento hasta el final de su trayectoria: hace arte, literatura, con la actualidad; filtra el material dado por la actualidad con su particular arte, mirada, prosa, estilo

El periodismo de Umbral, en estas colaboraciones radiofónicas y en casi todo lo que escribió para revistas y periódicos, es el periodismo de un escritor que se adapta al recuadro de la prensa, y en este caso de la radio. Mezcla la actualidad, a veces de forma muy ligera, muy tenue, con la cultura y con sus propias divagaciones literarias y humanas.

Su personalidad se muestra en su estilo, pues el estilo al final no es otra cosa que la plasmación literaria de esa personalidad ("el estilo es el hombre", como le gustaba repetir a nuestro escritor), a medio camino entre lo culto y lo popular, casi marginal, heterodoxa, "transgresora, insolente y creativa", que se muestra en la forma y en el contenido de sus artículos. Ahora sabemos que ese carácter y su impronta literaria se deben, en buena parte, a los orígenes del escritor, tanto familiares como escolares.

Se advierte en todo momento la voluntad experimentadora de Francisco Umbral. El escritor ya es consciente de que está buscando un estilo propio, y percibimos cómo aprovecha la gran libertad que le proporciona la emisora y la dirección de su primo José Luis Pérez Perelétegui. 


\section{Significación literaria y periodística de estas colaboraciones}

La significación de estos artículos es muy grande, porque en ellos podemos decir que asistimos al nacimiento de Francisco Umbral. Desde luego al nacimiento del pseudónimo, porque es a partir de aquí que empieza a utilizar este sobrenombre, pero también porque en estas colaboraciones radiofónicas vemos cómo se va formando el periodista que luego será Umbral. Podemos considerar el trabajo que desempeña en La Voz de León como su primer trabajo serio en el ámbito literario-periodístico. El escritor encuentra allí su gran oportunidad y no la desaprovecha.

Por otra parte, la calidad periodística y literaria de estas colaboraciones es muy alta. Generalizando, encontramos que alterna y fusiona perfectamente la actualidad periodística con su escritura, experimentando mucho y alcanzando grandes logros. Umbral filtra la actualidad para hacer sus artículos, muy periodísticos y muy literarios, sobre todo los pertenecientes a "El tiempo y su estribillo", mucho menos los de "Buenos días", de ambición mucho más poética.

Estas colaboraciones fueron escritas y emitidas en la radio entre los años 1958 y 1961, pero hoy las podemos considerar textos inéditos y su significación es importante porque hasta el momento no se habían estudiado en su conjunto. Es una pieza muy apreciable dentro de la obra de Umbral, teniendo en cuenta que las labores que desempeña en La Voz de León pueden considerarse su primer trabajo dentro del periodismo y la literatura, puesto que sus artículos previos en publicaciones universitarias y en El Norte de Castilla eran algo más puntual y aislado y pertenecían a la crítica literaria.

Debemos destacar otro hecho. Los artículos radiofónicos que Umbral escribe durante esta etapa contrastan de forma clara con las columnas de prensa que publica, durante un corto espacio de tiempo, en el Diario de León. Los textos de la radio son mucho más ricos periodística y literariamente; las columnas de prensa son más planas, neutras, políticamente correctas. Aunque esto se deba principalmente a imperativos políticos y a que ya se sabía reprendido por su actuación en el Cine-Club del Círculo Medina, la realidad es que los textos de La Voz de León apuntan con mucha mayor claridad hacia su columnismo futuro. Por último, hay que decir que ofrecen un objeto de estudio mucho más interesante que esas columnas del Diario de León. Es curioso observar cómo el escritor tardará mucho en volver a tener tanta libertad periodística y literaria, sólo tal vez cuando se aproxime al éxito en Madrid.

La personalidad de Umbral aparece muy perfilada, lo que llama mucho la atención. En estas colaboraciones ya están presentes las claves de lo que será en el futuro: mezcla de literatura y periodismo, influencia marcadísima de la poesía en la prosa, talante contestatario, polémico, muy crítico, incisivo, de izquierdas. Umbral ya es crítico social, que es lo que luego será en el futuro como columnista. En realidad aquí está el germen de su columnismo, y aunque estos textos nacieron para ser emitidos en la radio, se pueden considerar sus primeras columnas. 


\section{Referencias bibliográficas}

ARDAVÍN, C. X. (2003) Valoración de Francisco Umbral. Ensayos críticos en torno a su obra. Gijón: Llibros del Pexe, 2003

CABALLÉ, A. (1999) "Los comienzos de un escritor". En: Boletín de la Unidad de Estudios Biográficos, v.4, p. 9-20. (2004) Francisco Umbral. El frío de de una vida. Madrid: Espasa Calpe.

CASALS CARRO, M. J. (2000) "La columna periodística de esos embusteros días del ego inmarchitable". En: Estudios sobre el Mensaje Periodístico, n 6, Madrid: Servicio de Publicaciones de la Editorial Complutense, p. 31-51 http://revistas. ucm.es/index.php/ESMP/article/view/ESMP0000110031A/12902 [Acceso 10 Oct 2014]

CASTELLANI, J.P. (2012) "La cultura literaria de Francisco Umbral en las columnas periodísticas de El Mundo: presencia, función y alcance." En DÍEZ FERNÁNDEZ, J.I. (Ed.) Los placeres literarios: Francisco Umbral como lector. Majadahonda: Fundación Francisco Umbral.

CELMA VALERO, P. (Ed.) (2003) Francisco Umbral. Valladolid: Junta de Castilla y León-Universidad de Valladolid.

DE BURON-BRUN, B.(Ed.) (2009) Francisco Umbral: Una identidad plural. Pau: Université de Pau et de Pays de l'Adour.

(Ed.) (2010) Mujeres de Umbral. Pau: Université de Pau et de Pays de l'Adour. (2013) "El Barrio Húmedo paseo por las tabernas leonesas." En THION, D.; BELTRÁN, L.; HIBBS-LISORGUES, S. (Eds.) Tradición e interculturalidad. Las relaciones entre lo culto y lo popular. Zaragoza: IFC, p.157-165, http://ifc. dpz.es/recursos/publicaciones/32/90/14buron-brun.pdf [Acceso 2 Sep. 2013]

DIARIO DE LEÓN. León. Periodo consultado: Enero 1958- Marzo 1961

DÍEZ FERNÁNDEZ, J. I. (Ed.) (2012) Los placeres literarios: Francisco Umbral como lector. Majadahonda: Fundación Francisco Umbral.

EL NORTE DE CASTILLA. Valladolid. Periodo consultado: Marzo 1957- Marzo 1961

FERNÁNDEZ SANDE, M. y MARTÍNEZ RICO, E. (2014) "Primeras colaboraciones periodísticas y literarias de Francisco Umbral, textos recobrados: diario Proa y Revista Arco (1954-56)". En: Estudios sobre el Mensaje Periodístico, v.20 $\mathrm{n}^{\mathrm{o}} 1$ (enero-junio), Madrid: Servicio de Publicaciones de la Editorial Complutense, p. 357 - 376. Disponible en http://revistas.ucm.es/index.php/ESMP/article/ view/45237/42577 [Acceso 15 oct. 2014]

GARCÍA POSADA, M. (2009) "Introducción" En UMBRAL, F. Obra poética (1981-2001). Barcelona: Seix Barral.

GÓMEZ CALDERÓN, B. (2001) La evolución del columnismo de Francisco Umbral (1961-1997). Aspectos retórico-argumentativos. Tesis doctoral. Universidad de Málaga.

(2003) "Sobre la perspectiva articulística de Francisco Umbral: El magisterio de César González Ruano". En ARDAVÍN, C. X. (Ed.) Valoración de Francisco Umbral. Ensayos críticos en torno a su obra. Gijón: Llibros del Pexe, p. 224-241. (2004) Ladrón de fuego. La obra en Prensa de Francisco Umbral. Málaga: Asociación para la investigación y el desarrollo de la comunicación. 
GRACIA ARMENDARIZ, J. (1995) El artículo diario de Francisco Umbral (19571988): análisis y documentación. Tesis Doctoral. Universidad Complutense de Madrid. http://biblioteca.ucm.es/tesis/19911996/S/3/S3012301.pdf [Acceso 18 ag.2013]

(2003) "Orígenes del artículo diario de Francisco Umbral. Los años de formación, 1957-1969” en ARDAVÍN, C. X. (Ed.) Valoración de Francisco Umbral. Ensayos críticos en torno a su obra. Gijón: Llibros del Pexe.

(2003b) "La obra periodística de Francisco Umbral. Breve historia de una pasión diaria" en CELMA, M.P. (Ed.) Francisco Umbral. Valladolid: Junta de Castilla y León-Universidad de Valladolid. p.85-101

HERRERA, Á. A. (1991) Francisco Umbral ¿Yo soy así?. Madrid: Grupo Libro.

MACTAS, M.(1984) Las perversiones de Francisco Umbral. Madrid: Anjana.

MARTÍNEZ RICO, E. (2001) Umbral: vida, obra y pecados. Conversaciones. Madrid: Foca.

(2003) Umbral. Las verdades de un mentiroso ilustre. Gijón: Llibros del Pexe.

MAYORAL SÁNCHEZ, F. J. (1997) Transgresión, insolencia y creatividad en la prosa diaria de Francisco Umbral 1976-1994. Tesis Doctoral Universidad Complutense de Madrid. http://eprints.ucm.es/8767/1/S3034001.pdf [Acceso 12 Jul. 2013]

(1998) "Don Francisco Umbral y su lacerado lector". En: Estudios sobre el Mensaje Periodístico. $\mathrm{n}^{\circ} 4$, Madrid: Servicio de Publicaciones de la Editorial Complutense, p.191-202. Disponible en http://revistas.ucm.es/index.php/ ESMP/article/view/ESMP9898110191A/13045 [Acceso 6 Sep.2013]

PROA. León. 1958-1961. Periodo consultado: Abril 1958- Marzo 1961

SANZ VILLANUEVA, S.(2009) "Umbralianas" en SANZ VILLANUEVA, S. (Ed.) Francisco Umbral y su tiempo. Valladolid: Ayuntamiento de Valladolid.

UMBRAL, F. Guiones Radiofónicos de La Voz de León. Secciones: "Buenas noches" (29-5-1958 a 4-1-1959). "El Piano del Pobre" (7-1-1959 a 31-8-1959). "Buenos días" (5-10-1959 a 30-1-1960), "E1 Tiempo y su estribillo" (1-2-1960 a 4-2-1961). Majadahonda: Fundación Francisco Umbral. Documentación inédita. (1982) El hijo de Greta Garbo. Barcelona: Destino.

(1996) Las palabras de la tribu. Barcelona: Planeta.

(2004) Crónica de las tabernas leonesas. León: El Búho viajero.

YÑIGO DE TORO, M. T. (1963) Buenas noches. Valladolid: Sever.

\section{Notas}

Textos publicados en El Mundo: "Buenas noches ciudad" El Mundo, 10-8-2014 supl. V. p.1-3; "Gerardo Diego", "Buenas noches Francisco de Asis" El Mundo, 11-8-2014 p.12; "La sangre excesiva y escandalosa de Elvis Presley", "Elvis la pelvis" El Mundo 12-8-2014, p.12; "Buenas noches bebedor", "Buenas noches suburbio" El Mundo 13-8-2014 p.12; "José Hierro", "Buenas noches, poesía" El Mundo 14-8-2014, p.12. La editorial Planeta ha anunciado, a través de su página Web, 
la publicación prevista para el 15 de enero de 2015 del libro que recogerá una selección de estas colaboraciones de Umbral con el título "Diario de un noctámbulo".

2 Entrevistas realizadas con Aurora Fernández, administradora de La Voz de León entre 1956 y 1997. 29-7-2013, 17-8-2013 y 23-8-2013.

3 Entrevista realizada con Manuel Tomé, redactor de La Voz de León entre 1957 y 1961. 1-8-2013.

4 Entrevistas realizadas con José Antonio Pérez Perelétegui -primo de Francisco Umbral y hermano de José Luis Pérez Perelétegui (1931-2012) director de La Voz de León-. 16-7-2013, 18-7-2013, 27-82013 y 30-9-2013).

5 Proa, 11-1-1961, p. 9.

6 Proa, 13-1-1961, p. 6.

7 Diario de León, 4-2-1961, p. 3.

8 Comentario "Buenas noches, poeta", Fecha de emisión 29 de mayo de 1958. La Voz de León.

9 Comentario "Buenas noches; Escucha", Fecha de emisión 3 de septiembre de 1958. La Voz de León.

10 Comentario "Buenas noches, burgués". Fecha de emisión 28 de octubre de1958. La Voz de León.

11 Comentario "El tiempo y su estribillo". Fecha de emisión 1 de abril de 1960. La Voz de León.

12 Comentario "El piano del pobre". Fecha de emisión 8 de enero de 1959. La Voz de León.

13 Comentario "El piano del pobre”. Fecha de emisión 28 de febrero de1959. La Voz de León.

14 Comentario "El piano del pobre". Fecha de emisión 20 de julio de 1959. La Voz de León.

15 Comentario "El piano del pobre". Fecha de emisión 2 de julio de 1959. La Voz de León.

16 Comentario. "Buenos días". Fecha de emisión 23 de diciembre de 1959. La Voz de León.

17 Entrevista personal realizada con César Aller, poeta y escritor leonés. Director de la sección de cultura del Diario de León entre 1960 y 1962. 22-8-2013.

18 Comentario "El tiempo y su estribillo". Fecha de emisión 1 de febrero de 1960. La Voz de León.

19 Comentario "Buenas noches”. Fecha de emisión 24 de septiembre de 1958. La Voz de León.

20 Comentario "Buenas noches”. Fecha de emisión 17 de junio de 1958. La Voz de León. 